\title{
GEOMORFOLOGIA AMBIENTAL E AGRICULTURA FAMILIAR NA BACIA DO RIO IRATIM - GUARAPUAVA - PR ${ }^{1}$ \\ Enviromental geomorpholy and familiar agriculture on the river Iratim basin - Guarapuava - PR
}

\author{
Edivaldo Lopes THOMAZ²
}

\begin{abstract}
RESUMO
O objeto da Geomorfologia é o relevo e ele deve ser entendido quanto a sua forma, gênese, dinâmica entre outros elementos. Além disso, o relevo é o suporte para as atividades humanas e no caso da bacia do rio Iratim a principal atividade é a agricultura. No entanto, a prática agrícola tem causado a degradação dos solos, que é o principal fator de produção e reprodução familiar no âmbito da bacia. O presente trabalho enfoca a importância da geomorfologia ambiental no entendimento da degradação da paisagem, bem como no planejamento do uso dos solos agrícolas.

Palavras-chave: geomorfologia ambiental, relevo, agricultura familiar, degradação do solo.
\end{abstract}

\begin{abstract}
The object of the Geomorphology is the relief, and it must be understood in its form, genesis, and dynamic among others. Besides, the relief, is the support for human activities, and concerning to basin of Iratim river the main use is for agriculture. Nevertheless, the agricultural practice has been causing the degradation of the soils. The soil is the most important factor for production and reproduction of familial agriculture in the whole basin. The present work aims to show the importance of environmental geomorphology in the understanding of the landscape degradation, as well as in the planning for using agricultural soils.

Key-words: environmental geomorphology, relief, familial agriculture, soil degradation.
\end{abstract}

${ }^{1} \mathrm{O}$ trabalho é parte da dissertação de Mestrado - Análise empírica da fragilidade potencial da bacia do rio Iratim - Guarapuava - PR. São Paulo: USP - FFLCH, 2000.

2 Professor Assistente do Departamento de Geografia - Unicentro. 


\section{INTRODUÇÃO}

A região de Guarapuava foi uma das primeiras do Estado do Paraná a ser incorporada ao sistema econômico colonial entre os séculos XVIII e XIX. A organização do espaço, com base nos recursos oferecidos pela natureza, foi deixando suas marcas ao longo da História. Entre as conseqüências dessa organização tem-se erosão, poluição hídrica, desflorestamento e outras.

Dentre esses problemas procuramos destacar a degradação dos solos. Dessa forma, em trabalho de campo observamos aspectos ligados à agricultura familiar e constatamos de forma geral as dificuldades que os pequenos produtores enfrentam. Para tanto, fizemos um breve levantamento da evolução socioeconômica regional, além de destacarmos as características geomorfológicas e edafoclimáticas. Assim pudemos avaliar de modo preliminar as implicações desses elementos na sustentabilidade ambiental da agricultura familiar no âmbito da bacia do rio Iratim.

A metodologia utilizada para se entender a paisagem, bem como a degradação na bacia, baseia-se em TRICART (1977) Ecodinâmica e em ROSS (1994) "Análise empírica da fragilidade dos ambientes naturais e antropizados". As duas propostas encontram-se integradas, pois a de ROSS é um aprofundamento da anterior, no entanto ambas propõem uma taxonomia (classificação) dos ambientes fundada no grau de estabilidade - instabilidade da morfodinâmica atual.

De maneira geral procurou-se definir os seguintes aspectos: a) o quadro regional: solos, clima, vegetação, litologia, hidrografia e ocupação; b) análise morfodinâmica; c) estudo dos processos atuais para buscar a relação: morfogênese-pedogênese-ordenação; d) estabelecimento do grau de estabilidade morfodinâmica das unidades de paisagens. Além disso, elaboraram-se cartas temáticas a fim de espacializar os elementos estudados. Entre as principais cartas estão:

1- carta de índices de dissecação do relevo;

2- carta de classes de erodibilidade dos solos;

3- carta de classes de proteção aos solos conferida pela cobertura vegetal;

4- carta de fragilidade ambiental (síntese).

A partir desses procedimentos foi possível correlacionar a ocupação, dinâmica da paisagem e degradação ambiental. 


\section{CARACTERIZAÇÃO SOCIOECONÔMICA}

A ocupação e o desenvolvimento socioeconômico da Região Centro-Sul do Paraná teve uma ligação forte com a exploração dos recursos naturais, haja vista os ciclos econômicos: tropeirismo, ervamate, madeira, sistema faxinal e agricultura comercial.

Portanto, a organização do espaço regional e, por conseguinte, a área em estudo, esteve intimamente ligada ao processo de apropriação dos recursos naturais, sendo este permeado pelos "ciclos econômicos". Nele, havia um produto principal explorado responsável pela dinâmica da economia regional, enquanto outras atividades se desenvolviam e se organizavam paralelamente, dando suporte à atividade principal. (RIBEIRO, 1989).

Destaca-se o sistema faxinal, que se desenvolveu, principalmente, nas áreas de ocorrência das matas mistas. Esse sistema se caracteriza pela produção familiar e com uso coletivo da terra para a produção animal. Esta forma de organização foi muito importante, pois chegou a ocupar $1 / 5$ do território paranaense.

Entretanto, a economia madeireira começou a tomar impulso a partir de 1930, trazendo como conseqüências: deflorestamento das matas de araucária, pois, adquiriam apenas os pinheiros e não a terra; aumento da concentração da renda; núcleos com população itinerante; diminuição da erva-mate. Assim, houve prejuízo ao sistema faxinal/ agricultura de subsistência. (CHANG, 1988).

O extrativismo madeireiro entrou em declínio por volta de 1960, com ele, desestruturou-se o sistema de faxinal. Por outro lado, na época, houve o avanço do capitalismo na agricultura com vista a torná-la moderna, isso também corroborou para essa desestruturação. (CHANG, 1988).

As profundas transformações ocorridas na agricultura criaram um quadro de dualidade, ou seja, a penetração seletiva do capital formou uma agricultura moderna convivendo, ao mesmo tempo, ao lado de uma agricultura tradicional de subsistência. (RIBEIRO, 1989).

Essa realidade apontada por RIBEIRO (1989) permaneceu inalterada após uma década, pois grande parte da agricultura de subsistência ocupou áreas com sérias restrições morfopedológicas (solos rasos em áreas muito declivosas), não encontrando possibilidade de se modernizar. Por isso, a agricultura baseia-se no extrativismo de erva-mate, pinhão, cultivo de pequenas roças e criação de animais. Outro aspecto ligado à agricultura de subsistência, é que muitas vezes ela é praticada em área de reflorestamento em grandes propriedades. 
Já a agricultura capitalista moderna, ocupou as áreas de campo sem restrições ao uso de tecnologia. De maneira geral, o desenvolvimento econômico da região de Guarapuava pode ser considerado periférico dentro do Brasil, ou seja, essa região tem seu crescimento econômico dependente de outros centros econômicos mais desenvolvidos.

\section{CARACTERÍSTICAS AMBIENTAIS E DEGRADAÇÃO DOS SOLOS}

O clima da região em que está inserida a área em estudo, segundo MONTEIRO (1963) e MENDONÇA (1997) caracteriza-se pelas influências acarretadas pelos sistemas atmosféricos intertropicais (massa tropical atlântica, massa tropical continental e massa equatorial continental) e polares (massa polar atlântica), havendo, contudo, participação moderada dos sistemas intertropicais e participação mais efetiva do sistema extratropical. Essa dinâmica confere à região um clima com característica subtropical.

A precipitação média para a área em estudo é de aproximadamente $1960 \mathrm{~mm}$. Contudo, há anos com pluviosidade superior a $2100 \mathrm{~mm}$, ou até mais, como foi o caso extremo no ano de 1983, com 3168,4 mm. A chuva se distribui ao longo do ano com todos os meses apresentando precipitação pluviométrica média entre 140 a 200 mm, à exceção do mês de agosto com média de 96,7 mm (ver figura 1). Pode ocorrer, porém, meses com alta pluviosidade como julho de 1983 (471,8 mm), maio de 1992 (512,8 mm), abril de 1998 (518 mm) (IAPAR, 1998). Assim, são comuns os eventos torrenciais (aguaceiros), que causam sérios prejuízos. Outra característica climática são as temperaturas negativas, com média superior a 10 geadas por ano. (IAPAR, 1994).

Em relação às chuvas intensas, pode-se destacar alguns eventos significativos ocorridos em Guarapuava, entre 1976 e 1998: setembro de 1983 (110,8 mm), julho de 1983 (140,3 mm), maio de 1992 (165,2 $\mathrm{mm}$ ) e abril de 1998 (206 mm em 12 horas).(IAPAR, 1998).

Os solos são provenientes de rochas basálticas com os seguintes tipos: Latossolo Bruno, Terra Bruna estruturada, solos hidromórficos, Cabissolos e Litólicos. Esses dois últimos são os mais frágeis por serem solos rasos e ocuparem posição em vertentes de fortes declives, geralmente acima de $20 \%$. 


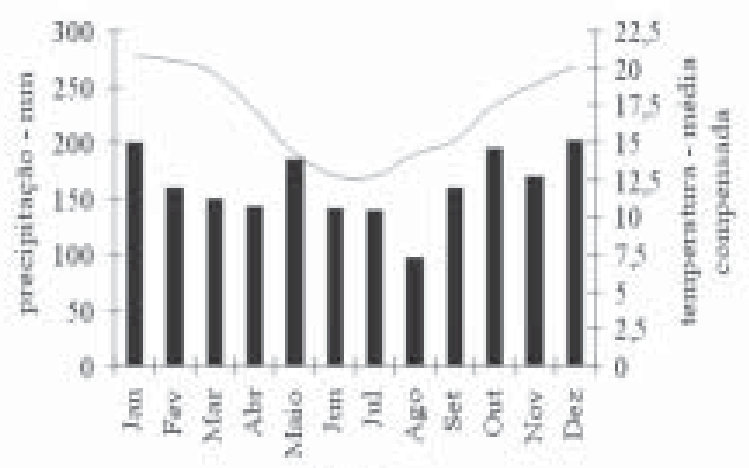

mềs

FONTE: IAPAR, 1998.

A ocorrência de chuvas torrenciais ocasiona graves problemas, principalmente a degradação dos solos que é agravada quando as atividades agrícolas são feitas em solos mais frágeis, de maior erodibilidade e com baixa aptidão agrícola. Acrescenta-se ainda, manejo dos solos e o uso de técnicas inadequadas como agravante para a sustentabilidade ambiental (anexo 1).

Além disso, em área de agricultura mecanizada constatou-se em muitos casos o uso excessivo de máquinas, evidenciado pela presença de solo pulverizado (baixa presença de agregados ou torrões). Outro aspecto diz respeito à compactação em subsuperfície (15 a $20 \mathrm{~cm}$ ). Essa compactação foi identificada pela observação de raízes (raízes pivotantes) de ervas daninhas que se apresentavam tortas, indicando esforço para romper a camada adensada. Em pastagem, também foi evidenciado tal processo, causado pelo pisoteio do gado, contudo em profundidade menor (cerca de $5 \mathrm{~cm}$ ).

Essa alteração física do solo diminui a porosidade e, por conseguinte, diminui a infiltração, reduzindo a capacidade de armazenamento de água do solo. Por outro lado, aumenta o escoamento superficial, desencadeando processos erosivos. Ainda em relação ao processo erosivo, tanto laminar como em sulco, ele é incrementado pela prática de queimadas (coivara). Principalmente, em agricultura de subsistência, que pratica a rotação de terras e utiliza-se do fogo para o preparo do solo (anexo 2). Com as queimadas, o solo fica exposto, pois 
a cobertura vegetal é consumida pelo fogo. No entanto algumas plantas possuem morfologia que as protege contra o fogo, notadamente as que formam touceiras como o rabo-de-burro (Andropogon sp), capim barba-de-bode (Aristida pallens), caraguatá (Erydium spp), capim caninha (Adropogon lateralis) e outras.

Dessa forma, a área degradada com intenso processo erosivo laminar e em sulco, bem como com prática de queimada, possui solo com baixa capacidade de armazenamento d'água, tornando-se comum o aparecimento de plantas com características xerofíticas, que passam a predominar nessas áreas, a exemplo das plantas indicadas acima.

Essa forma de uso do solo abre caminho aos processos erosivos com a perda do horizonte superficial, por conseguinte, há perda gradativa de suporte de biomassa (rarefação de plantas) ocasionada pelo empobrecimento do solo e da baixa capacidade de retenção hídrica.

O processo, explicitado acima, foi evidenciado primeiramente por técnicos da Embrapa (Centro Nacional de Pesquisa de Floresta Curitiba), que verificaram em uma área da bacia do rio Lajeado (município de Guarapuava) em que alguns solos já haviam perdido aproximadamente $20 \mathrm{~cm}$ do horizonte superficial (tabela 1).

TABELA 1 - TIPO DE SOLO, OCUPAÇÃO E ESPESSURA DO HORIZONTE A EM CM IDENTIFICADOS NA BACIA DO RIO LAJEADO - GUARAPUAVAPR

\begin{tabular}{lcc}
\hline \multicolumn{1}{c}{ Solo } & Ocupação & Espessura do horizonte A em cm. \\
\hline Latossolo Bruno & Floresta & 55 \\
Latossolo Bruno & Pastagem & 40 \\
Latossolo Bruno & Agricultura & 30 \\
Terra bruna & Pastagem & $25-30$ \\
Terra bruna & Agricultura & 30 \\
Cambissolo & Pastagem & 25 \\
Cambissolo & Pousio & $20-25$ \\
Litólico & Floresta & $20-25$ \\
Litólico & Pastagem & $5-15$ \\
Litólico & Agricultura & $5-15$ \\
\hline
\end{tabular}

FONTE: EMBRAPA - CNPF, 1999.

O relevo, de modo geral, encontra-se bastante dissecado pela drenagem, grosso modo, a tendência nesse caso é o predomínio do escorrimento superficial d'água, as expensas de uma menor infiltração. A alta pluviosidade, média de $1960 \mathrm{~mm}$ ano, confere à região de Guarapuava, um excedente hídrico com potencial para causar erosão, 
que é agravado pelas características morfopedológicas (relevo-solo) e pelas práticas de manejo inadequadas às características do meio físico.

De maneira geral, o relevo nessa área apresenta uma seqüência típica, topos ligeiramente aplanados (baixa declividade e solo relativamente profundo), segmento de vertentes retilíneas (alta declividade e solo incipiente), por fim, uma ruptura de declive em forma de patamar (declividade média e solo profundo com horizonte $\mathrm{Bt}$ ). $\mathrm{O}$ não entendimento da dinâmica dessas formas de relevo é que causa forte degradação dos solos.

Dessa forma, ao se utilizar os topos planos com pastagem e agricultura, por exemplo, ocorre mudança hidrológica na vertente com tendência ao escoamento superficial concentrado para as partes mais baixas do relevo, passando pelas vertentes retilíneas e pelos patamares. Portanto, se as águas não forem controladas nos topos e a vegetação das vertentes retilíneas não for preservada, tem-se uma degradação também dos patamares, por erosão laminar, em sulco e por soterramento, perdendo-se significativas áreas principalmente com Terra Bruna Estruturada. Esse processo também ocorre nos setores de vertentes côncavas, quando há alteração hidrológica nos topos aplanados.

Assim, a agricultura familiar, além de sofrer as conseqüências do famoso "tripé", compra mal seus insumos, produz mal e acaba vendendo mal seus excedentes, ocupa geralmente os piores solos (com baixa aptidão agrícola), o que dificulta, ainda mais, a manutenção da família. Por isso, é comum a incorporação de novas áreas para o plantio, mesmo que essas não tenham condições ideais.

O entendimento do processo de degradação das terras na bacia do rio Iratim e principalmente a que ocorre nas pequenas propriedades agrícolas, pode se dar de acordo com o esquema proposto por TRICART (1987), (anexo 3). No referido esquema, percebem-se as inter-relações entre o meio natural e a sociedade. Em relação ao meio natural, consideram-se suas características genéticas, suas potencialidades e fragilidade, acerca da sociedade considera-se sua relação econômica, cultural, tecnológica etc. Isso vai se refletir na estrutura agrária, e, por conseguinte, resulta numa maior ou menor degradação das terras agrícolas de acordo com os elementos envolvidos. A compreensão dessa imbricada relação sociedade e natureza permite o entendimento do processo de degradação que ocorre em algumas áreas da referida bacia. 


\section{CONCLUSÃO}

A agricultura moderna tem conseguido cada vez mais criar agrossistemas (artificiais) e fugir das influências edafoclimáticas. Contudo, para a agricultura familiar, a terra (solo) em conjunto com as condições ambientais, principalmente o clima, influencia de maneira direta a produção agrícola. Além disso, na região de Guarapuava, parte da agricultura familiar foi excluída pelo processo de modernização agrícola e encontra sérias restrições para garantir sua sustentabilidade (reprodução).

A agricultura familiar utiliza de forma intensa os solos, mesmo em áreas com sérias restrições morfopedológicas, iniciando um círculo vicioso, pois ao utilizar solos mais frágeis (baixa aptidão agrícola), esses acabam se degradando mais rapidamente, diminuindo a produtividade e, por conseguinte, diminui também a renda familiar.

Esse processo faz com que novas áreas sejam incorporadas ao processo produtivo. Portanto, aumenta a pressão sobre os remanescentes de florestas Ombrófila Mista, florestas secundárias e capoeiras em regeneração. Mesmo sendo comum a prática de rotação de terras na bacia, ela não garante a sustentabilidade ambiental devido à forma como é praticada: em vertentes declivosas, solos rasos e com uso de fogo.

A degradação ocorre de forma mais intensa do médio para o baixo curso, pois nesse setor da bacia, a interação relevo-solo, além do uso da terra ora comentado, conferem uma maior fragilidade para o uso agrícola.

Dessa forma, o planejamento socioambiental em bacia hidrográfica se constitui em um dos meios para conservar solo e água, bem como melhorar as condições socioeconômicas dos agricultores. A Geomorfologia tem um papel integrador acerca dos estudos ambientais, já que o entendimento da dinâmica do relevo é importante para o planejamento ambiental. A proposta metodológica utilizada no presente trabalho, TRICART (1977) e ROSS (1994), apresenta-se como alternativa ao planejamento agrícola, em conjunto com propostas já consagradas no meio agronômico como as de aptidão agrícola, capacidade de uso da terra e outras.

Assim, o planejamento agrícola enfocando principalmente as características e a dinâmica do relevo (vertentes) por meio de unidades de fragilidade, é uma forma de se conhecer a dinâmica do meio físico de forma sistêmica e que complementado pelos aspectos 
socioeconômicos, permite a integração dos estudos da relação sociedade e natureza (socioambiental). No caso desse estudo, a Geomorfologia ambiental visa propor solução a degradação ambiental, especialmente à conservação de solo e água.

Por fim, a Geomorfologia Ambiental visa compreender a dinâmica do sistema ambiental principalmente os humanizados para que essa ocupação não desencadeie processos geomórficos superficiais como: erosão, escorregamentos, inundações etc. Com isso, busca-se entender a relação entre os elementos: ocupação, morfodinâmica (degradação) e ordenação-planejamento, com vista à conservação do sistema ambiental.

\section{REFERÊNCIAS}

CHANG, M. Y. Sistema Faxinal: uma de organização camponesa em desagregação no centro-sul do Paraná. Londrina: IAPAR, 1988. Bol. téc., 22.

EMBRAPA. Empresa Brasileira de Pesquisa Agropecuária - CNPf. Levantamento expedito e aptidão dos solos da micro-bacia do rio Lajeado e caracterização climática do alto curso do rio Jordão. Colombo-PR, 1999.

IAPAR. Cartas climáticas do Paraná. v. 18. Londrina: IAPAR,1994.

IAPAR. Histórico climático 1976-1996 (resumo) da estação meteorológica da cidade de Guarapuava - PR. 1998.

MENDONÇA, F. A. A contribuição do zoneamento climático na elaboração de diagnóstico ambiental de bacias hidrográficas: o exemplo da Bacia do Rio Tibagi/PR. Boletim Climatológico (Faculdade de Ciências e Tecnologia, UNESP), Presidente Prudente, São Paulo, 1997.

MONTEIRO, C. A. F. O clima da região Sul. Região Sul. Tomo I. Biblioteca Brasileira. Rio de Janeiro: IBGE, 1963.

ROSS, J. L. S. Análise empírica da fragilidade dos ambientes naturais e antropizados. Revista do Departamento de Geogralia-FFLCH-USP, São Paulo, n. 8, 1994. 
RIBEIRO, A. G. As transformações da sociedade e os recursos da natureza na região de Palmas e Guarapuava. Bol. Geografia- UEM, Maringá, ano 7, 1989.

THOMAZ, E. L. Análise empírica da fragilidade potencial do rio Iratim Guarapuava PR. São Paulo, 2000. Dissertação (Mestrado) - USP/FFLCH.

TRICART, J. Ecodinâmica - FIBGE/SUPREN. Rio de Janeiro, 1977.

TRICART, J. Approche systemique de la dégradation des terres. Revue de Geomorphoiogie Dynamique, Paris, v. 19, n. 4, Paris, 1987. 


\section{ANEXO 1 - RAVINA EM TERRA BRUNA ESTRUTURADA COM CULTIVO} DE MANDIOCA

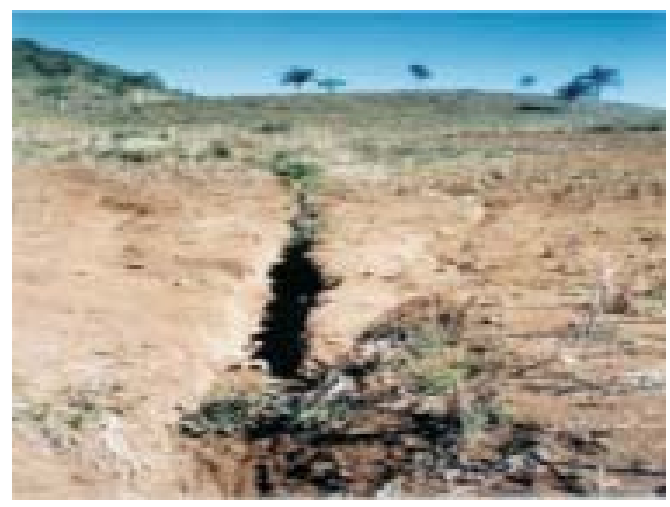

FONTE: THOMAZ, 2000.

\section{ANEXO 2 - ESQUEMA DE ROTAÇÃO DE TERRA EM AGRICULTURA FAMILIAR}

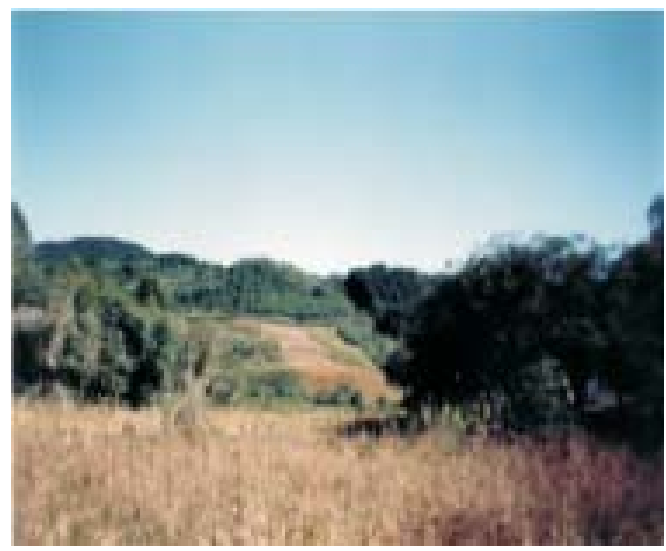

FONTE: THOMAZ, 2000. 
ANEXO 3 - ESQUEMA DA DEGRADAÇÃO DAS TERRAS AGRÍCOLAS

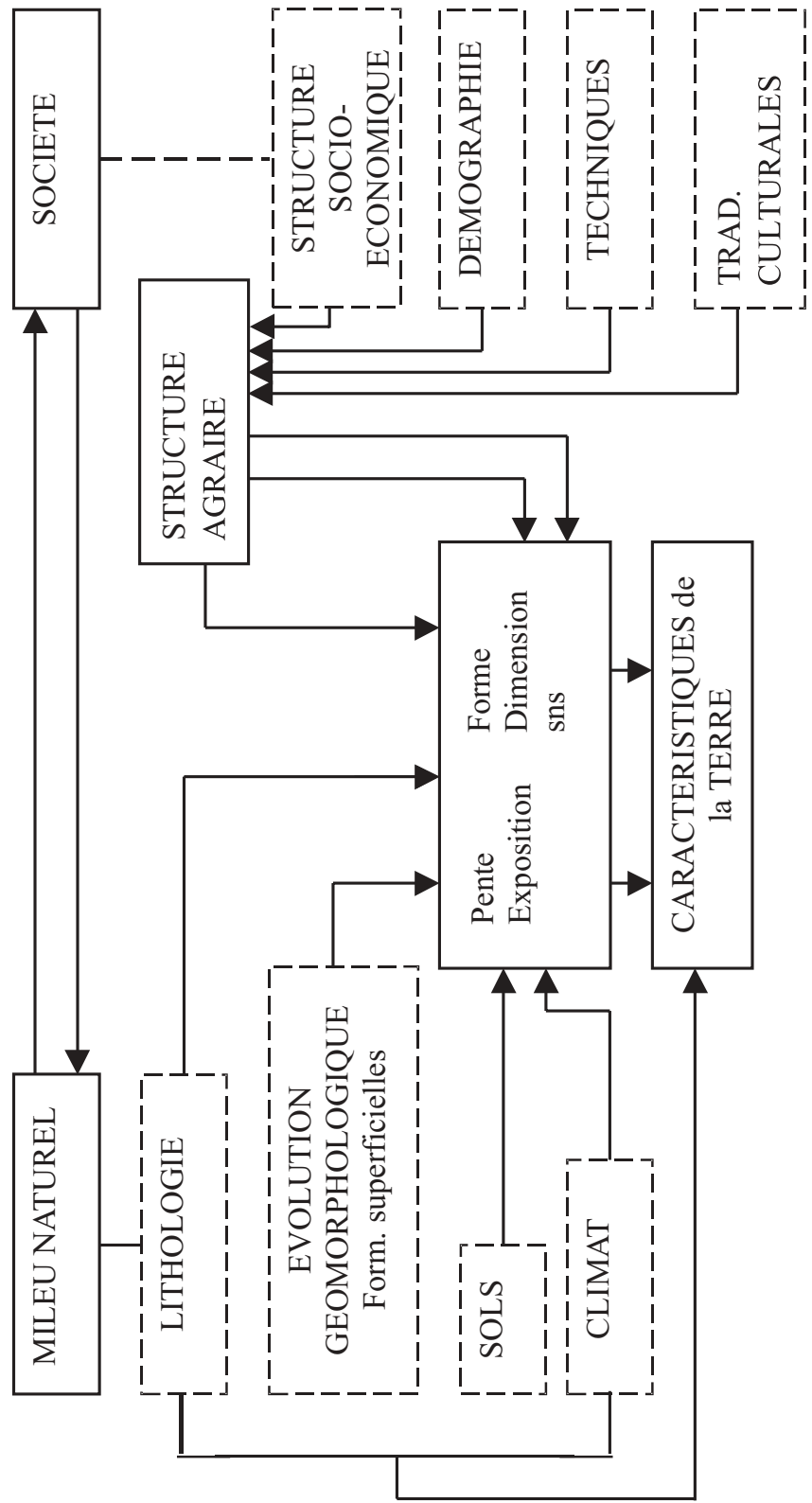

FONTE: TRICART, 1987. 